\title{
A Guide for Novice Researchers: Design and Development Research Methods
}

\author{
Timothy J. Ellis and Yair Levy \\ Nova Southeastern University, \\ Graduate School of Computer and Information Sciences, \\ Fort Lauderdale, Florida, USA
}

\author{
ellist@nova.edu, levyy@nova.edu
}

\begin{abstract}
Understanding the type of research methods that may best fit a given research agenda can be daunting task for novice researchers. In many instances, the problem can seem to be overwhelming in that the novice does not possess the basic familiarity with the fundamental terms and concepts of some of the more commonly used approaches to make an informed decision. This paper provides the novice researcher with a basic set of concepts and terms associated with conducting design and development studies, one of the foundational research approaches in the informing sciences. A six phase design and development framework adopted from prior system development methodology literature is presented. Additionally, examples to help the novice researcher better grasp the proposed framework are discussed.
\end{abstract}

Keywords: Design and development research, research methods for novices, foundational research approaches, informing novices researchers.

\section{Introduction}

The novice researcher - a graduate student, for example - faces numerous challenges when attempting to add to the body of knowledge through an original, scholarly inquiry. The novice researcher must first identify a meaningful problem that can serve as the focal point for the study (Ellis \& Levy, 2008). She or he must anchor and position that study in the existing body of knowledge (Levy \& Ellis, 2006). The researcher then needs to select an appropriate study type based on the nature of the problem and guidance from the literature (Ellis \& Levy, 2009). The selection of the appropriate study type represents nothing more than the end of the beginning of the challenge. The novice researcher must appropriately implement her or his study within the accepted parameters for that study type.

A classic bootstrap problem can emerge for the novice researcher at the implementation phase.

Material published as part of this publication, either on-line or in print, is copyrighted by the Informing Science Institute. Permission to make digital or paper copy of part or all of these works for personal or classroom use is granted without fee provided that the copies are not made or distributed for profit or commercial advantage AND that copies 1) bear this notice in full and 2) give the full citation on the first page. It is permissible to abstract these works so long as credit is given. To copy in all other cases or to republish or to post on a server or to redistribute to lists requires specific permission and payment of a fee. Contact Publisher@InformingScience.org to request redistribution permission.
Although there is an abundance of studies of any given research type reported in the peer-reviewed literature, those reports are often rather frustrating when used as models. Due to a number of constraints such as publisher imposed size restrictions and author attention to the specific and unique aspects of the study, general principles are often buried within detail if not omitted altogether. Research 
methodology texts are certainly a valuable resource for implementation guidance for many study types, but do, unfortunately, give inadequate attention to some of the less well-known but still valuable approaches to information systems research such as design and development research.

The goal of this paper is to provide the novice researcher with fundamental set of concepts and terms necessary for overcoming the bootstrap problem associated with conducting design and development studies by presenting a framework of the underlying principles for that type of research. Before that framework can be understood, however, a foundation in what constitutes research-level design and development efforts, especially in contrast to product development, is necessary.

\section{What Design and Development Research Is - and Is Not}

Literature throughout the informing sciences domain, including information systems (Hasan, 2003; Hevner, March, Park, \& Ram, 2004; Nunamaker, Chen, \& Purdin, 1991; Peffers, Tuunanen, Rothenberger, \& Chatterjee, 2007) and education (Richey \& Klein, 2007; van den Akker, 2000), explores design and development research. Hasan (2003) offered a concise definition for design and development research as the "disciplined investigation conducted in the context of the development of a product or program for the purpose of improving either the thing being developed or the developer" (p. 7). Hevner et al. (2004) particularized the defintion to the information systems domain by defining "Design science ... creates and evaluates IT [Information Technology] artifacts intended to solve identified organizational problems" (p. 77). Richey and Klein (2007) specified the definition to the education domain by defining this type of research as: "the systematic study of design, development and evaluation processes with the aim of establishing an empirical basis for the creation of instructional and non-instructional products" ( $p$. $\mathrm{xv}$ ). Regardless of domain differences and individual points of emphasis, two essential aspects of the defining characteristics of design and development research emerge: the design and development research results in production of some form of artifact, and the process is indeed research, not to be confused with product development.

\section{Artifacts}

Design and development research can perhaps best be viewed as performing a "bridging" function in the research cycle (Nunamaker et al., 1991). Such research begins with the initial conceptualization of a problem and culminates in evaluation of the impact of one or more artifacts on ameliorating that problem. Design and development research focuses on building that bridging artifact that can serve to strengthen the interaction in the conceptualization and evaluation cycle. Figure 1 illustrates the central concept behind the design and development research framework using the bridging artifact. 


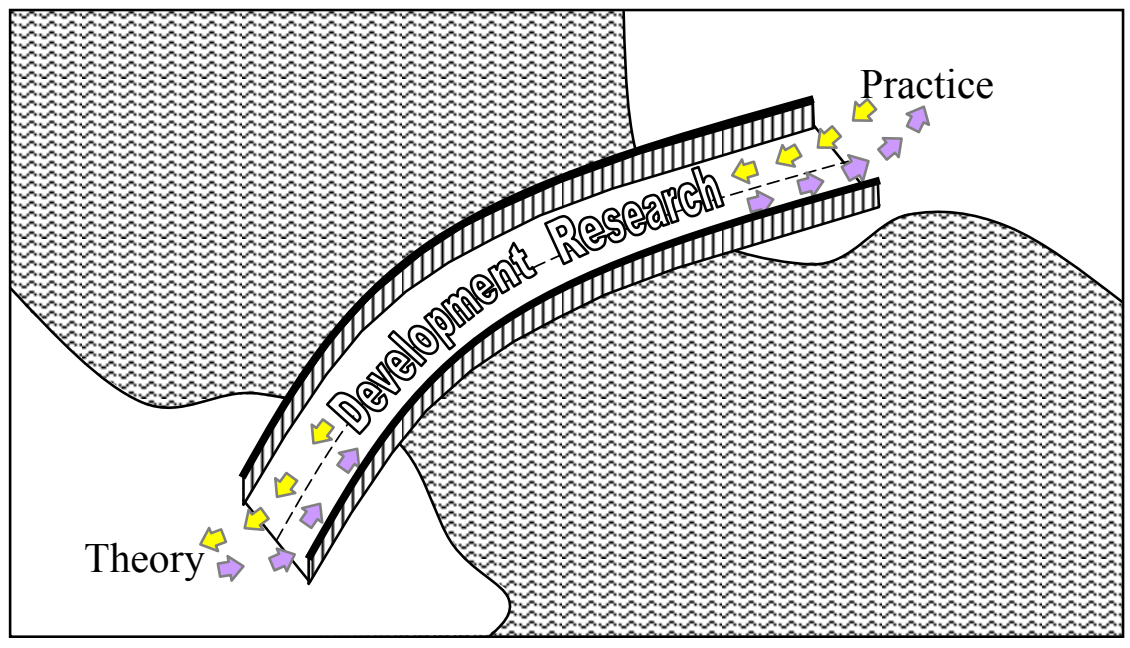

Figure 1: Design and development research framework

These artifacts can include the development of a new tool, product, or process (Richey \& Klein, 2007). The artifacts of design research can also include some less obvious outcomes, such as development of (Hevner et al., 2004):

- new theories explaining the underlying cause of the problem;

- new design and development models such as the Spiral Model of the systems development life cycle (SDLC);

- new methods and processes for implementing existing models or using existing tools; and

- previously untested application of tools, models, or methods to a problem in a new context. Often, approaches that had previously been proven effective in addressing one type of problem in a given context are effective in addressing an essentially different but in some aspects similar problem or context.

\section{Research, Not Product Development}

It is important to distinguish between design and development research and product development. Quite conceivably, one could develop a product that enjoys great commercial success, brings the developer both fame and fortune, but does not meet the criteria for research. In general, research entails: addressing an acknowledged problem, building upon existing literature, and making an original contribution to the body of knowledge (Ellis \& Levy, 2008).

\section{Problem driven}

Identification of the problem motivating the study should be the first step in design and development research (Peffers et al., 2007). Although product development might also be motivated by an identified problem, the problems driving research are in several ways quite different. Problems that can motivate most design and development research are, in general, poorly defined and complex; one-dimensional, straightforward problems can motivate product development, but usually not research. In addition, in order for design and development type of research to present potential for making a meaningful contribution, the problem must be one that can in fact be addressed by some form of human creativity or interaction. Design and development research would not be appropriate if the development of some form of artifact does not present any potential for addressing the problem (Hevner et al., 2004). 


\section{Literature Based}

Literature support is vital for all research as a means of placing the study in the context of the existing body of knowledge (Levy \& Ellis, 2006) and establishing the presence, importance, and nature of the problem driving the research (Ellis \& Levy, 2008). Specific to design and development types of studies, a number of design decisions must be made throughout the process; the theoretical basis for the decisions reached is likewise supported through the literature (van den Akker, 2000).

\section{Original contribution}

"The key differentiator between routine design and design research is the clear identification of a contribution to the archival knowledge base of foundations and methodologies" (Hevner et al., 2004, p. 81). Development research can add to the knowledge base in a number of ways. The contribution could take the form of creating connections between distinct areas within the domain, such as the technological and behavioral areas within information systems (Nunamaker et al., 1991). An example of this type of contribution would be creating a system that would make text mining technology useful for document analysis (Plaisant, Rose, Yu, Auvil, Kirschenbaum, Smith et al., 2006). Often, the conclusions of the research process expands the existing knowledge base by leading to new areas for research (Richey \& Klein, 2007); a study that built a model for using wiki technology in the classroom (Wang \& Turner, 2004) certainly suggests the need for a study to test the value of that model.

Some additional more practical characteristics that distinguish research-level development include:

1. Systematic documentation of the process that includes a discussion of design choices made, options considered, and rationale for the alternative selected (van den Akker, 2000).

2. Use of rigorous, accepted research methods throughout the process (Hevner et al., 2004).

3. Empirical testing of the artifact developed (Hevner et al., 2004; van den Akker, 2000).

4. Communication of the results of the process (Hevner et al., 2004).

\section{A Framework for Design and Development Research}

Each type of research has accepted procedural guidelines specific to it. There are a number of overarching factors that are applicable to all modes of scholarly research. First, all research must be driven by a problem that is appropriate for the type of research being conducted (Ellis \& Levy, 2008). Second, all research must be based on research questions that can be answered by the type of research being conducted. Third, all research must acknowledge the assumptions, limitations, and delimitations upon which the research is based. Fourth, research can only produce results that are obtainable from the methods employed. Finally, all research must communicate conclusions that are supportable by the results. A useful framework for research methods must address both the considerations specific to that form of inquiry and the factors that are applicable to all forms of research (Ellis \& Levy, 2009).

\section{The Major Steps in Design and Development Research}

There is a degree of variance in the literature in terms of both number and names of the major milestones in design and development research. Nunamaker et al. (1991)., identified five major milestones: a) construct the conceptual framework; b) develop the system architecture; c) analyze and design the system; d) build a prototype; and e) test and evaluate the prototype. Peffers et al. 
(2007) expanded on Nunamaker et al. (1991) and Hevner et al. (2004) to develop a 6-phase model including: a) identify the problem motivating the research; b) describe the objectives; c) design and develop the artifact; d) subject the artifact to testing; e) evaluate the results of testing; and f) communicate those results. Figure 2 outlines the 6-phase design and development framework. We will follow such approach as the framework for design and development research studies.

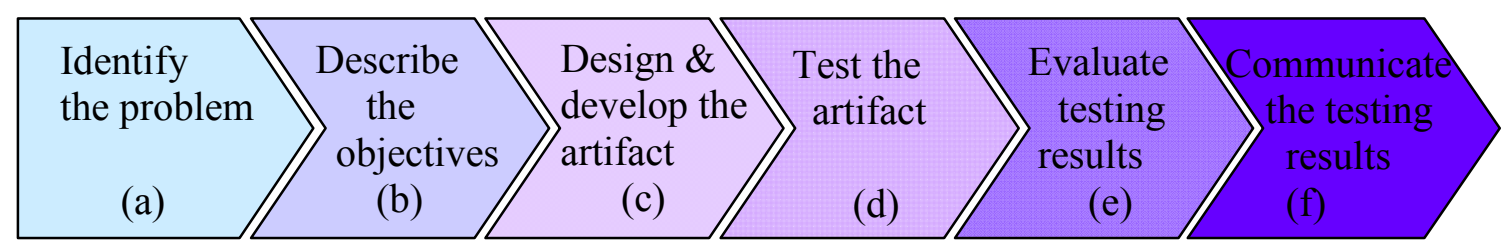

Figure 2: The 6-phase design and development research approach

\section{Identify the problem}

The importance of starting research in general (Ellis \& Levy, 2008), and design and development studies in specific (Hasan, 2003; Hevner et al., 2004; Nunamaker et al., 1991; Peffers et al., 2007; Richey \& Klein, 2007; van den Akker, 2000) with a clearly articulated problem is widely recognized. Not all problems, however, are research-worthy and not all research-worthy problems are appropriate for design and development research methods (Ellis \& Levy, 2008).

Problems of a number of different types can drive design and development studies. Newly emerging or evolving conditions often create situations in which there is no product, tool, or model available to correct the problem. This lack of a product or tool that could potentially alleviate the troublesome situation certainly constitutes a research-worthy problem applicable to design and development research (Richey \& Klein, 2007). For example, during the mid-1980s manufacturing companies found the need to keep large inventories of the parts necessary to build their products both expensive and difficult to manage. The companies desired a way to have just the right number of component parts available at any given time, but there simply was not a way to ensure that the parts necessary would be available when required, but only when required. This problem served as a driving force for the development of electronic data interchange (EDI) systems. Interestingly, the success of EDI systems in addressing the problem for large companies created a second problem. EDI systems were extremely complex, unique solutions that were quite expensive. The need for the 'just in time' inventory management was present for the smaller and medium enterprises (SMEs) as well. However, the costs associated with EDI systems made them prohibitively expensive, again creating another research-worthy problem, thereby serving as one of the problems driving the development of XML (Goldfarb \& Prescod, 2002).

Sometimes, the emerging or evolving condition is either very poorly understood or extremely complex. In such cases, the problem supersedes the lack of a tool or product. The real issue is the absence of a workable method of conceptualizing how to address the problem. This lack of a way to model a solution constitutes a worthy problem applicable to design and development research (Hevner et al., 2004; Richey \& Klein, 2007). For example, as software development became increasingly more complex and resource consuming, the classic 'waterfall' SDLC methodology did not adequately model the process, leading to the development of a newer model, the spiral model (Pressman, 1997). During the late 1990s, however, with the rapid growth of Internet and Webbased applications, the traditional SDLC methodologies including the spiral model become too time consuming and lacked the ability to rapidly change as customers' requirements changed. The result was the development of the agile methodology that is centered on adaptive requirements consumer centered rapid development (Chan \& Thong, 2009).

In yet other cases, an unresolved condition in one domain might be similar to a problem that a given product, tool, or model has successfully addressed in a different but in some fashion similar 
domain, creating the problem that we don't know how to adapt or instantiate (Hevner et al., 2004) the solution to this new situation. For example, managing large school systems to ensure optimal learning experiences for all students is an ongoing challenge. Vast amounts of data are generated and stored by school systems, but these data are not effectively used to inform decisions to optimize the learning experiences. Data mining has been used effectively to help businesses optimize the customer experience, but there are significant differences between the business and education environments, creating the need for a method for applying data mining technology to the education environment (Luan, 2002).

Despite the distinctions noted above, all problems that drive design and development research share some common characteristics. Hevner et al. (2004) identified five salient factors common to problems underlying design and development studies:

1. Environmental factors such as requirements and constraints are poorly defined

2. An inherent complexity in the problem and possible solutions

3. A flexibility and potential for change of possible solutions

4. A solution at least partially dependent on human creativity

5. A solution at least partially dependent on collaborative effort

\section{Identify objectives}

The objectives for any research endeavor are encapsulated in the research questions that underlie the study (Ellis \& Levy, 2009). Since the answers to the research questions are in essence the contributions the study makes in addressing the motivating problem, the questions must: a) be clearly related to that problem, and b) not already have known and/or documented answers.

The type of study being conducted constrains the research questions that can be answered by the study; the research questions establish the framing for the study (Richey \& Klein, 2007). The framing for design and development research is focused on the design, development, testing, and evaluation of an artifact (Peffers et al., 2007). Some typical research questions associated with design and development studies are listed in Table 1.

Table 1: Sample research questions

\begin{tabular}{|l|l|}
\hline Research Phase & Research Question Example \\
\hline Identify Objectives & $\begin{array}{l}\text { What requirements must the product (tool, model) meet in order to ad- } \\
\text { dress the problem? }\end{array}$ \\
\hline Design \& Develop & $\begin{array}{l}\text { What are the major decision points in the design and development proc- } \\
\text { ess, the options available at each point, and the optimal choices among } \\
\text { those options? }\end{array}$ \\
\hline Test \& Evaluate & $\begin{array}{l}\text { In what ways does the product developed meet and fail to meet the re- } \\
\text { quirements specified? }\end{array}$ \\
\hline Communicate & What changes to the product are indicated? \\
\hline
\end{tabular}

\section{Design and develop the artifact}

As mentioned previously, it is important to anchor the process of designing and developing the artifact in the literature. In information sciences, the waterfall, spiral, and rapid prototyping system development methods (SDMs) are well established (Pressman, 1997). Similarly, in education, the Analysis, Design, Development, Implementation, Evaluation (ADDIE) and Dick and Carey models are among the many accepted instructional design processes (Gagne, Briggs, \& Wagner, 1992; Jonassen et al., 1999). The novice researcher would be well advised to follow one 
of the accepted SDMs or instructional design models in framing their approach to design and develop an artifact.

Regardless of the process model followed, there are three factors usually included in this phase of design and development research. In general, the process entails: building a conceptual framework, followed by designing the system architecture, and ending with building a prototype for testing and evaluation (Hasan, 2003; Nunamaker et al., 1991):

Build a conceptual framework, including system functionalities and requirements. The development of the requirements for the system is crucial in that the requirements serve the vital role of connecting the product being developed with the problem driving that development. Techniques used to develop the requirements specification include use of expert panels, interviews with potential end users, and a review of the literature.

Based upon that framework, analyze the alternative solutions and design a system architecture. It is vital to identify the important decision made during the design process, describe the alternatives considered, and discuss the rationale supporting the alternative selected. As mentioned above, this systematic documentation of the design process is one of the factors that distinguish design and development research from product development (van den Akker, 2000).

From the architectural design, create of some form of prototype of the tool or model being developed. The prototype is, in most instances, the primary artifact created in the design and development research endeavor. The exact nature of the prototype varies based on the goal of design and development research - development of a tool, a model, or a novel instantiation of a tool or model. Regardless of the nature of the artifact being designed and developed, building a prototype is necessary to proceed to the test and evaluate step in the process.

\section{Test and evaluate}

It is necessary to demonstrate that the artifact developed meets the functionalities and requirements established for it during the design and development phase. Another critical part of the testing and evaluation is the validity of the artifact developed in the context of the problem described. The researcher must ensure that the developed prototype is indeed applicable in the proposed context and can demonstrate some viable results in addressing the problem.

The exact manner in which the testing and evaluation is conducted varies depending on the nature of the artifact being developed and the resources available to the researcher. Some of the more commonly used methods to test and evaluate artifacts of design and development research activities include direct observations from pilot studies (Hasan, 2003) and indirect indicators from surveys, questionnaires, interviews, and other observations (Richey \& Klein, 2007). Regardless of the method or methods used to test and evaluate the artifact, there are three essential considerations for this phase of design and development research:

1. Establish the ways in which the product does and does not meet the functionalities and requirements identified for it ...

2. ... by using accepted, literature-supported processes ...

3. ... in order to ensure acceptance of the value of the artifact.

\section{Communicate results and conclusions}

To a very great extent, the clear and complete communication of the results and conclusions of a research endeavor constitutes the contribution of the study to the body of knowledge. Researchers produce a considerable amount of new knowledge through their studies. However, without properly documenting and disseminating such results, neither a contribution to the body of knowledge 
nor advancement in research are made (Leedy \& Ormrod, 2010). The results and conclusions are closely related to the research questions driving the study. The results are, in fact, the answers and supporting evidence - to those research questions. The conclusions form the connection between those answers and the problem driving the research and constitute the contribution of the study to the body of knowledge. Just as the type of research question that can be answered is dependent on the type of study being conducted, the nature of the results and conclusions varies according to the type of research being conducted (Mertler \& Vannatta, 2009).

Results. Just as there can be research questions related to each of the phases of design and development research there are associated results (Hasan, 2003). The nature of the evidence available to support the answers to the research questions is directly related to the methods used to derive answers to the questions and does vary widely(Richey \& Klein, 2007). The range of possible methods used in design and development research - and the resulting evidence - is quite vast; a small example, based upon the four research questions illustrated in Table 1 is presented in Table 2 .

Table 2: Forms of evidence

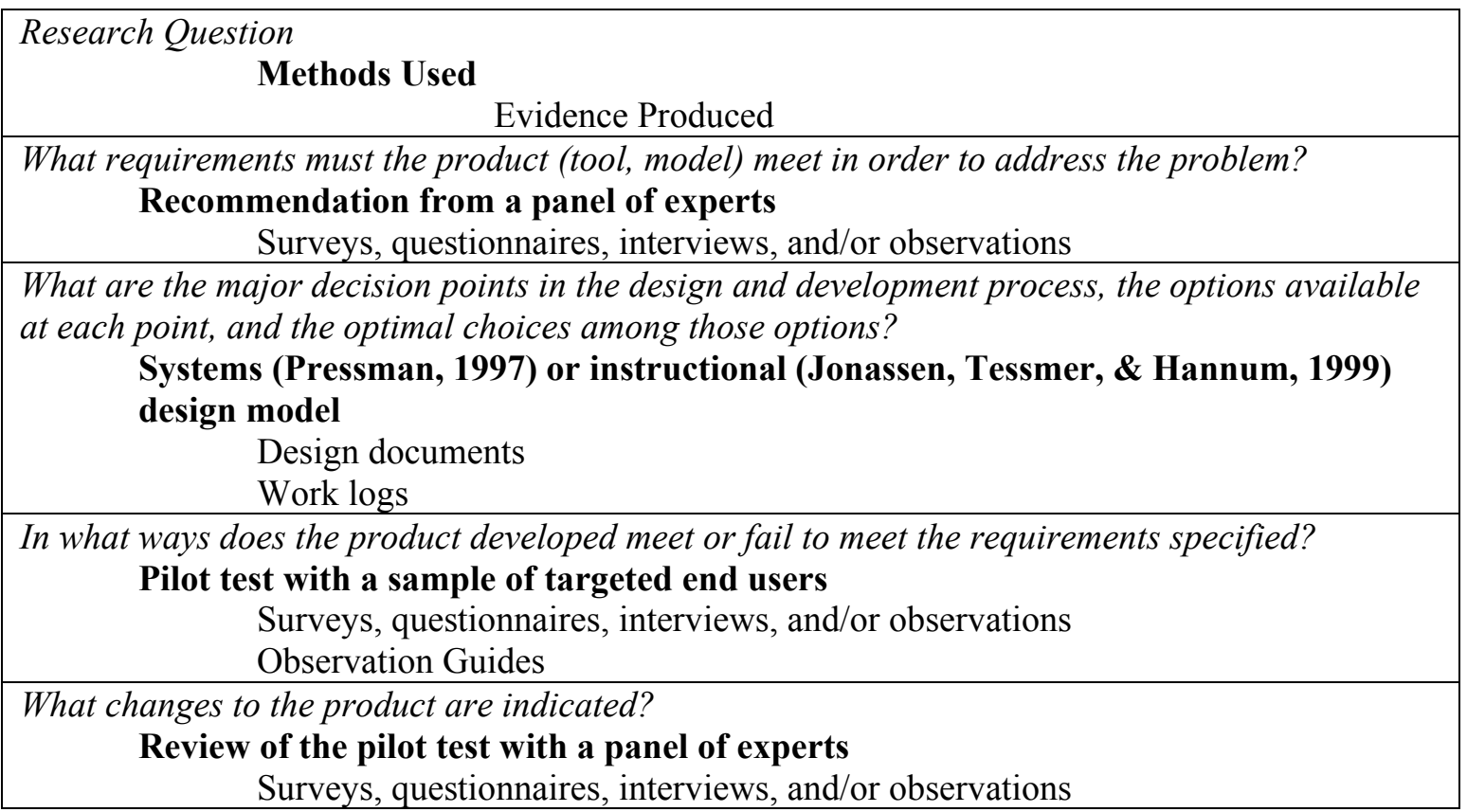

Conclusions. There are a number of different types of conclusions that can be drawn from design and development research, depending both the research questions driving the study and the type of product - tool, model, or instantiation - being developed (Richey \& Klein, 2007). Some of the more common types of conclusions resulting from design and development studies include:

1. Indicators for a new theoretical construct (Richey \& Klein, 2007). Nunamaker et al. (1991) observed: "The synthesis and expression of new technologies and new concepts in a tangible product, however, can act as both the fulfillment of the contributing basic research and as an impetus to continuing research" (p. 29).

2. Inspiration for developing new hypotheses, identifying new variables, and expanding insight into richer explanation of already discovered causal relationships (Richey \& Klein, 2007). 
3. Better understanding of design process itself: "The major knowledge to be gained from development research is in the form of (both substantive and methodological) 'design principles' to support designers in their task" (van den Akker, 2000, p. 9).

4. Discovery of heuristics and broadly applicable principles regarding design, development, or use of a tool or model (Richey \& Klein, 2007).

\section{Overarching Factors}

Regardless of the type of study being conducted, there are underlying aspects that must be identified. Underlying all research efforts are assumptions, or things that the researcher accepts as true without concrete proof. It is vital for the research to clearly present those 'givens' either as part of their argument or as part of the study limitations. No study provides answers that are indisputably "true"; the limitations or the factors that could potentially cause the researcher to draw incorrect conclusions from the study must be identified and explicitly reported. Not only must the limitations be identified but the provisions to promote the reliability and validity of the results of the study must be detailed (Mertler \& Vannatta, 2009). Finally, no study provides answers that are universally applicable; the delimitations or intentional constrictions that the researcher placed on the study and that serve as its boundaries must be stated.

\section{Assumptions}

The assumptions upon which a study rests usually flow from the research methods employed (Leedy \& Ormrod, 2010). In design and development research, for example, if an expert panel is used as part of the process of forming the requirements for the product during the identify objectives phase, it is usually assumed that the members of the panel are representative of experts in the given field. If a pilot study is utilized as part of product evaluation, it is usually assumed that the participants in the pilot study are representative of typical target users for the product.

\section{Limitations, reliability, and validity}

As in the case of assumptions, the limitations of a study are usually associated with the research methods employed (Leedy \& Ormrod, 2010). The believability of the results and conclusions of a study are directly related to how those results were obtained. For any study, factors outside the researchers control can negatively impact that believability. Following the examples started in the previous section, the following limitations might be identified in design and development research: a) since the requirements identified for the product will be established through the use of an expert panel and will represent the expert opinion of the members of that panel, those requirements might not be the only or even optimal set of requirements; b) since the participants in the pilot study will all be volunteers who could withdraw from the study at any time, the results of the product testing might not truly reflect the effectiveness of the product in meeting the criteria established for it.

Although limitations are unavoidable, careful attention to establishing the reliability and validity of the methods employed in the study can significantly reduce the possibility that the results indicate something that is in fact not the case. The best way to establish the reliability and validity of the methods employed is to follow accepted processes and use established tools as they were designed to be used. In the case of design and development research, for example, if the opinions of an expert panel will be used to develop the requirements for the product, those opinions should be determined through an accepted consensus-building process such as the Nominal Group Technique or Delphi Process (Delbecq, Ven, \& Gustafson, 1975). If a pilot study is to be used to test and evaluate the product, a form of accepted usability testing could be employed (Shneiderman, Plaisant, Cohen, \& Jacobs, 2009). Whenever surveys, interviews, or questionnaires are included 
in the research design, proper development and use of the instruments is crucial (Alreck \& Settle, 1995).

\section{Delimitations}

Design and development research studies are inherently subject to impact by environmental factors (Richey \& Klein, 2007), especially time: "Design-science research is perishable. Rapid advances in technology can invalidate design-research results before they are implemented" (Hevner et al., 2004, p. 99). In order for the design and development work to be research, the researcher must establish the contribution of study makes to the body of knowledge while at the same time clearly acknowledging the threats to generalization - the delimitations - of the results of the study. Some typical delimitations of design and development research include:

1. An instructional design model developed for planning asynchronous learning networks for adult college students might not be applicable to students in younger age groups or educational levels.

2. A model for employing knowledge management technologies to accelerate new employee acculturation in military facilities might not be applicable to similar programs in other, less structured organizations.

3. A media-enhanced interface for an e-commerce site specializing in women's apparel might not be effective for other products or products targeted at male shoppers.

\section{Concluding Remarks}

The aim of this paper was to provide a guide to novice researchers on design and development research. The value and role of design and development research within the domain of information systems research was explored, followed by an introduction to a 6-phase design and development framework. The design and development phases included: a) identify the problem motivating the research; b) describe the objectives; c) design and develop the artifact; d) subject the artifact to testing; e) evaluate the results of testing; and f) communicate those results.

It is important to remember that this paper presents only a framework for research. As such, it serves as a good starting point for design and development studies, but is certainly not a comprehensive resource. For each of the phases additional search into the literature will be necessary. Although the exact nature of that additional literature support will depend on the specifics of the study, some starting points are summarized in Table 3.

Table 3: Additional Resources

\begin{tabular}{|ll|}
\hline Phase & Resource \\
\hline Identify the Problem & Ellis and Levy (2008) \\
Describe the Objectives & Peffers et al. (2007) \\
& Richey and Klein (2007) \\
Design and Develop the Artifact & Pressman (1997) \\
& Gagne et al. (1992) \\
Test and Evaluate the Artifact & Alreck and Settle (1995) \\
& Richey and Klein (2007) \\
Communicate the Testing Results & Hart (1998) \\
& Williams and Colomb (2007) \\
\hline
\end{tabular}




\section{References}

Alreck, P. L., \& Settle, R. B. (1995). The survey research handbook (2nd ed.). Boston: Irwin McGraw-Hill.

Chan, F. K. Y., \& Thong, J. Y. L. (2009). Acceptance of agile methodologies: A critical review and conceptual framework. Decision Support Systems, 46(4), 803-814.

Delbecq, A. L., Ven, A. H. V. d., \& Gustafson, D. (1975). Group techniques for program planning: A guide to nominal group and delphi process. Glenview, IL: Scott Foresman.

Ellis, T. J., \& Levy, Y. (2008). Framework of problem-based research: A guide for novice researchers on the development of a research-worthy problem. Informing Science: the International Journal of an Emerging Transdiscipline, 11, 17-33. Retrieved from http://www.inform.nu/Articles/Vol11/ISJv11p017-033Ellis486.pdf

Ellis, T. J., \& Levy, Y. (2009). Towards a guide for novice researchers on research methodology: Review and proposed methods. Issues in Informing Science and Information Technology, 6, 323-337. Retrieved from http://iisit.org/Vol6/IISITv6p323-337Ellis663.pdf

Gagne, R. M., Briggs, L. J., \& Wagner, W. W. (1992). Principles of instructional design. New York: Harcourt Brace Jovanovich College Publishers.

Goldfarb, C. F., \& Prescod, P. (2002). XML handbook (4th ed.). Upper Saddle River, NJ: Prentice Hall PTR.

Hart, C. (1998). Doing a literature review: Releasing the social science research imagination. London, UK: Sage Publications.

Hasan, H. (2003). Information systems development as a research method. Australasian Journal of Information Systems, 11(1), 4-12.

Hevner, A. R., March, S. T., Park, J., \& Ram, S. (2004). Design science research in information systems. Management Information Systems Quarterly, 28(1), 75-105.

Jonassen, D. H., Tessmer, M., \& Hannum, W. H. (1999). Task analysis methods for instructional design. London: Lawrence Erlbaum Associates.

Leedy, P. D., \& Ormrod, J. E. (2010). Practical research: Planning and design (9th ed.). Upper Saddle River, NJ: Prentice Hall.

Levy, Y., \& Ellis, T. J. (2006). A systems approach to conduct an effective literature review in support of information systems research. Informing Science: the International Journal of an Emerging Transdiscipline, 9, 181-212. Retrieved from http://www.inform.nu/Articles/Vol9/V9p181-212Levy99.pdf

Luan, J. (2002). Data mining and its applications in higher education. New Directions for Institutional Research, (113), 17-36.

Mertler, C. A., \& Vannatta, R. A. (2009). Advanced and multivariate statistical methods: Practical application and interpretation (3rd ed.). Los Angeles, CA: Pyrczak Publishing.

Nunamaker, J. F., Chen, M., \& Purdin, T. D. M. (1991). Systems development in information systems research. Journal of Management Information Systems, 7(3), 89-101.

Peffers, K., Tuunanen, T., Rothenberger, M. A., \& Chatterjee, S. (2007). A design science research methodology for information systems research. Journal of Management Information Systems, 24(3), 45-77.

Plaisant, C., Rose, J., Yu, B., Auvil, L., Kirschenbaum, M. G., Smith, M. N., et al. (2006). Exploring erotics in Emily Dickinson's correspondence with text mining and visual interfaces. Proceeding of the International Conference on Digital Libraries, Chapel Hill, NC, USA pp. 141-150.

Pressman, R. S. (1997). Software engineering: A practitioner's approach (4th ed.). New York: McGraw Hill.

Richey, R. C., \& Klein, J. D. (2007). Design and development research. Mahwah, NJ: Lawrence Erlbaum Associates, Publishers. 
Shneiderman, B., Plaisant, C., Cohen, M., \& Jacobs, S. (2009). Designing the user interface: Strategies for effective human-computer interaction (5th ed). Reading, MA: Addison-Wesley.

van den Akker, J. (2000). Principles and methods of development research. In J. van den Akker, R. M. Branch, K. Gustafson, N. Nieveen \& T. Plomp (Eds.), Design approaches and tools in education and training. Norwell, MA: Kluwer Academic Publishers.

Wang, C.-M., \& Turner, D. (2004). Extending the wiki paradigm for use in the classroom. Proceeding of the International Conference on Information Technology: Coding and Computing, Las Vegas, Nevada, 255-259.

Williams, J. M., \& Colomb, G. G. (2007). The craft of argument (3rd ed.). New York: Longman.

\section{Biographies}

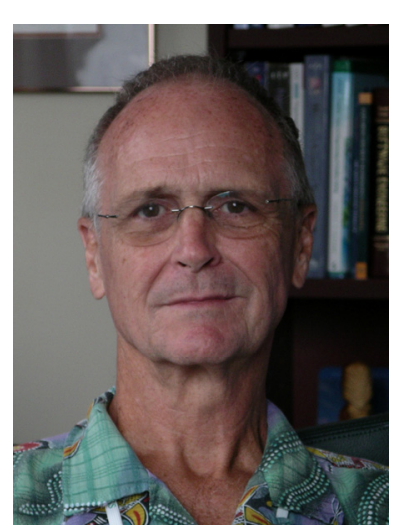

Dr. Timothy Ellis obtained a B.S. degree in History from Bradley University, an M.A. in Rehabilitation Counseling from Southern Illinois University, a C.A.G.S. in Rehabilitation Administration from Northeastern University, and a Ph.D. in Computing Technology in Education from Nova Southeastern University. He joined NSU as Assistant Professor in 1999 and currently teaches computer technology courses at both the Masters and Ph.D. level in the School of Computer and Information Sciences. Prior to joining NSU, he was on the faculty at Fisher College in the Computer Technology department and, prior to that, was a Systems Engineer for Tandy Business Products. His research interests include: multimedia, distance education, and adult learning. He has published in several technical and educational journals including Catalyst, Journal of Instructional Delivery Systems, and Journal of Instructional Multimedia and Hypermedia. His email address is ellist@nova.edu. His main website is located at http://www.scis.nova.edu/ ellist/

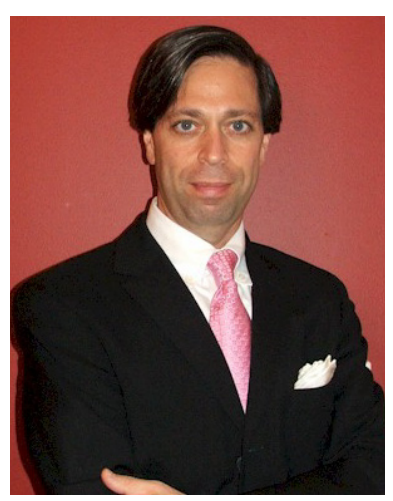

Dr. Yair Levy is an associate professor at the Graduate School of Computer and Information Sciences at Nova Southeastern University. During the mid to late 1990s, he assisted NASA to develop e-learning systems. He earned his Bachelor's degree in Aerospace Engineering from the Technion (Israel Institute of Technology). He received his MBA with MIS concentration and Ph.D. in Management Information Systems from Florida International University. His current research interests include cognitive value of IS, of online learning systems, effectiveness of IS, and cognitive aspects of IS. Dr. Levy is the author of the book "Assessing the Value of e-Learning systems." His research publications appear in the IS journals, conference proceedings, invited book chapters, and encyclopedias. Additionally, he chaired and cochaired multiple sessions/tracks in recognized conferences. Currently, Dr. Levy is serving as the Editor-in-Chief of the International Journal of Doctoral Studies (IJDS). Additionally, he is serving as an associate editor for the International Journal of Web-based Learning and Teaching Technologies (IJWLTT). Moreover, he is serving as a member of editorial review or advisory board of several refereed journals. Additionally, Dr. Levy has been serving as a referee research reviewer for numerous national and international scientific journals, conference proceedings, as well as MIS and Information Security textbooks. He is also a frequent speaker at national and international meetings on MIS and online learning topics. To find out more about Dr. Levy, please visit his site: http://scis.nova.edu/ levyy/ 